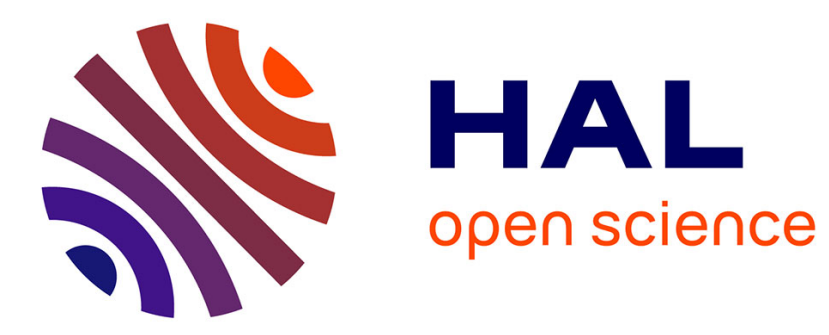

\title{
The Exchange on Practice: An Issue for the Development of Novice Ergonomists in Peru in a Context Where Practices of Ergonomic are Heterogeneous
}

Mirtha Mestanza, Camille Toulisse, Camille Bachellerie, Danie Jon, Alexis Chambel

\section{To cite this version:}

Mirtha Mestanza, Camille Toulisse, Camille Bachellerie, Danie Jon, Alexis Chambel. The Exchange on Practice: An Issue for the Development of Novice Ergonomists in Peru in a Context Where Practices of Ergonomic are Heterogeneous. International Ergonomics Association 21st Triennial Congress, Jun 2021, Vancouver, Canada. pp.492-499, 10.1007/978-3-030-74602-5_69 . hal-03277366

\section{HAL Id: hal-03277366 https://hal.science/hal-03277366}

Submitted on 3 Jul 2021

HAL is a multi-disciplinary open access archive for the deposit and dissemination of scientific research documents, whether they are published or not. The documents may come from teaching and research institutions in France or abroad, or from public or private research centers.
L'archive ouverte pluridisciplinaire HAL, est destinée au dépôt et à la diffusion de documents scientifiques de niveau recherche, publiés ou non, émanant des établissements d'enseignement et de recherche français ou étrangers, des laboratoires publics ou privés. 


\section{The exchange on practice: an issue for the development of novice ergonomists in Peru in a context where practices of ergonomic are heterogeneous}

MESTANZA Mirtha (1) TOULISSE Camille (2) BACHELLERIE Camille (3) JON Danie (4-5) CHAMBEL Alexis (4-6)

1 Ergonomist, General manager, Aquaergo, LIMA, Perú

2 Ergonomist, Head of the internal Occupational Health Service of Département de l'Ain, France

3 Ergonomist, Ph.D student, Conservatoire national des arts et métiers, CREAPT, France

4 Ergonomist, Ph.D student, AECTT-EVS UMR 5600, Université Lumière Lyon 2, France

5 Kardham, France

6 Parcours Doctoral National en Santé Travail, France

Abstract. Ergonomics in Peru is influenced by a very heterogeneous practice: the ergonomics of activity and human factors. In this context, the JPR days in Peru allow novice practitioners to share their practices and make them evolve.

Keywords: Exchange of practice, ergonomics of the activity, human factors, Peru

\section{Introduction}

The Junior Practices in reflection Committee (JPR) was born out of a two-fold observation; the existence of problems specific to young practitioners and the lack of space to instruct those. From that basis, it was proposed to the SELF (French Speaking Ergonomics Society) to create a committee dedicated to ex-changes on the practice of ergonomics for and by junior practitioners. This committee has a twofold objective of creating an ephemeral framework for exchanges between junior practitioners while at the same time articulating these exchanges with the various instances that make up the profession and manufacture the discipline. Since its creation in 2014 and at a rate of about three days per year, it has brought together nearly 200 participants from all over France but also from vari-ous fields of ergonomics practice (occupational health service, consultant, inter-nal, doctoral student, etc.). Finally, these spaces of exchange have crossed borders, with a first office in Quebec from 2014 to 2017 and an office in Peru since 2018. The interest of this symposium is to present what has been developed by the committee in terms of exchanges on practice while opening this presentation to other forms of practice. These axes will take the form of four communications. The first communication will return to the theoretical foundations of the JPR Committee. The second paper will present the story of a young practitioner. Without wanting to be representative, it will serve as an example to show what is discussed in the JPR meeting days. The third communication will present the implementation of the exchange on practice, and we will be able to illustrate here the methodology we use and the intermediate objects that it mobilizes. The fourth communication will come back to the specificities of the deployment of the office in Peru and issues that this may raise.

In this fourth communication, we will speak exclusively about the development of the SELF JPR Commission office in Peru and the implementation of the days of reflection on the practice. Indeed, this document does not aim to measure the impact of the exchange days on the practice of young Peruvian ergonomists because until now two days of exchanges have taken place since the creation of the commission. Due to the global situation, the 2020 events could not take place and will be 
postponed to the year 2021. Thus, this document based on the 2 days realized aims to show: the development of the JPR days in Peru, how they allow novice practitioners to share their practices and to make them evolve, the differences with France as well as the difficulties encountered, and all this in a context where the practice of ergonomic are heterogeneous.

\section{Context}

The observation on the diversity of professional practices in ergonomics has been shared for many years in France (Daniellou, 2003, Daniellou, 2008, Falzon, 2019) and these different forms of practices and areas of specialization are recognized. The JPR are part of this tradition of taking a close interest in all forms of practices.

Peru, like other countries in America, is influenced by the two currents of ergonomics: activity ergonomics and human factors ergonomics. In this country, we find novice ergonomists trained in one of the two currents, or novice ergonomists with mixed training (Cromer and Mestanza, 2019). Novice practitioners trained in human factors ergonomics focus their practice on a normative approach. This practice focuses on man as a machine, and the adaptation of the machine to man is their main concern (Darses \& Montmollin, 2006). On the other hand, those trained in activity ergonomics aim to transform work, supported by an analysis centered on the activity of the workers. Moreover, this practice focuses on the human being as an actor in the work system (Darses \& Montmollin, 2006).

15 new ergonomists are trained each year in Peru, and this for all training (courses, University Diploma and Master). Moreover, with various training and practical these novice Peruvian ergonomists find themselves alone in the field and without accompaniment. That is to say that they do not have opportune spaces to express their difficulties, mistakes and also successes during their first years of practice. Ergonomists experience professional difficulties that have an impact both on them and on their interventions (Viau-Guay, 2009). There are conferences or courses that they attend and where they can express themselves in Peru, but with a learning rather than an exchange objective. Thus, in a context where ergonomics is new and practices are diverse, it is important to generate discussion spaces that allow novice Peruvian ergonomists to have reflexive exchanges about their practice (Schön, 1983). These spaces for exchange could enable them acquire strategies, compare their analyses, see the advantages and disadvantages of each practice, and enrich their own.

\section{Peruvian office of The Junior Practices in reflection Commitee}

The idea of implementing exchange days on the practice in Peru emerges thanks to two favorable factors. The first factor is the presence in Peru of three ergonomists trained in France. They know, from their training, the importance of adopting a reflective posture, regularly and intentional, in order to become aware of one's way of acting, or reacting, in the practice of ergonomics (Schön, 1983). The second factor is the knowledge of the success of the SELF'S JPR Committee in France and Quebec, during the SELF congress symposium in 2016: "De l'échange sur la pratique à son enrichissement" (From the exchange on the practice to its enrichment).

Aware of the difference in the reality of training and practice of ergonomics between France and Peru, we knew that reproducing the exchange days on the practice in Peru would be a great challenge. For this reason, it was essential to participate virtually (one of the three ergonomists) in a few days of exchange of the JPR Committee in France. This way, a link has always been kept with France with the members of the French JPRs office. During these days, it was possible to sort out the elements 
replicable or not in Peru on the structuring as well as the engineering of the discussion set up in France (Cromer and Mestanza, 2019). These will be developed in the construction and development part of the Peruvian JPRs.

Thus, an office of The Junior Practices in reflection in Peru was created in 2018 with the support of the SELF. The SELF has validated this as a Committee that fosters the exchange on practice and emerging communities of novice practitioners in ergonomics of activity. The Peruvian office is run by three ergonomists trained in France. It has been agreed so far to organize 2 days per year. The main objectives of these exchanges are kept intact and are:

- To provide a space for exchanges and discussions.

- Fostering debate between practitioners (ergonomics of the activity and human factors).

- Participate in building new practices.

- Enabling participants to develop their networks.

\section{Construction and development of the junior practices Days in Peruvian ergonomics}

The Day before: Exchange days requires prior preparation. Here, we will present the organization of the days, highlighting the elements that can be replicated or not from France to Peru. ${ }^{1}$

Just like in France, the members of the office create the necessary conditions for the realization of the day and also everything concerning logistics. The place and the schedule are strategically chosen because in Peru there are many ergo-nomics professionals; who work alternately between the city and the mining industry and therefore it is necessary to adapt to the schedules. The network of novice ergonomists is small, which facilitates the organization of the days. The organizers propose, by email, between 3 or 4 possible dates. Once the date and the place are chosen, a communication is made on social networks (Facebook, Instagram, LinkedIn ) as well as on the SELF website in order to reach other possible participants. Registration is free as in France and is done by email.

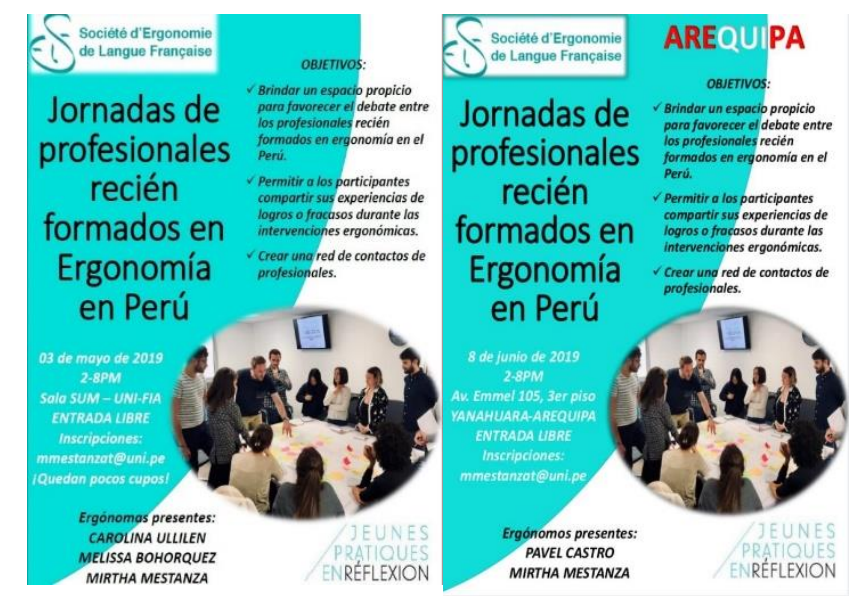

Fig.1. Information poster for the Peruvian Practical Reflection Days in 2019

\footnotetext{
${ }^{1}$ Bachellerie C. et al. (2021). Building spaces for discussion: getting the diversity of practices speak, IEA $21^{\text {st }}$ Triennial Congress
} 
Unlike in France, not all participants are ergonomists, so it is necessary to broaden the field of influence to occupational physicians and other health, hygiene, and safety professionals. Moreover, some of them are not available for a whole day because of their work. The agreed schedules for the two days carried out were in the afternoon (14:00 to 18:00). Registrations are limited to 12 people for organizational reasons and to guarantee a quality of exchange, as the organizers can moderate small groups of 4 people especially as the participants are not familiar with this type of days. Indeed, they are used to attending conferences where participants listen and ask a few questions at the end of the presentation. Moreover, some participants are reluctant to show their work for fear of being judged, confidentiality of information, etc., which requires the facilitator to provide a caring setting. Finally, the facilitator asks the participants to bring items related to their current interventions (plans, presentations, photos, videos, etc.) to facilitate the exchanges.

The Day: As in France, the organizer opens the day and the participants are welcomed in a selected room to encourage exchanges. Each participant introduces themself and expresses they expectations (Cromer \& Mestanza, 2019).

Unlike in France, where the committee is beginning to be known, the participants do not know the Committee, its objectives and the methodology of the day's proceedings. It is therefore necessary to have a very detailed explanation of the operating rules. In the two days carried out in Lima and Arequipa, there were 6 participants per day. For this reason, it was not necessary to divide the participants into small groups. The exchanges were therefore carried out with the whole room. Each participant had between 30 and 50 minutes to share their intervention while exchanging with their peers. There was no specific preparation time before the day, but participants were asked to bring their work (slides, plans, models, etc.). There were no specific themes developed, as it was first necessary to familiarize participants with this new exchange methodology.

The first day session of the Peruvian office took place on May 3, 2019 in Lima from 14:00 to 18:00, in the premises of the Universidad Nacional de Ingenieria. The novice practitioners presented their current interventions and the topics discussed were varied. We show below a summary illustrating the topics discussed and the picture of the participants of the day.
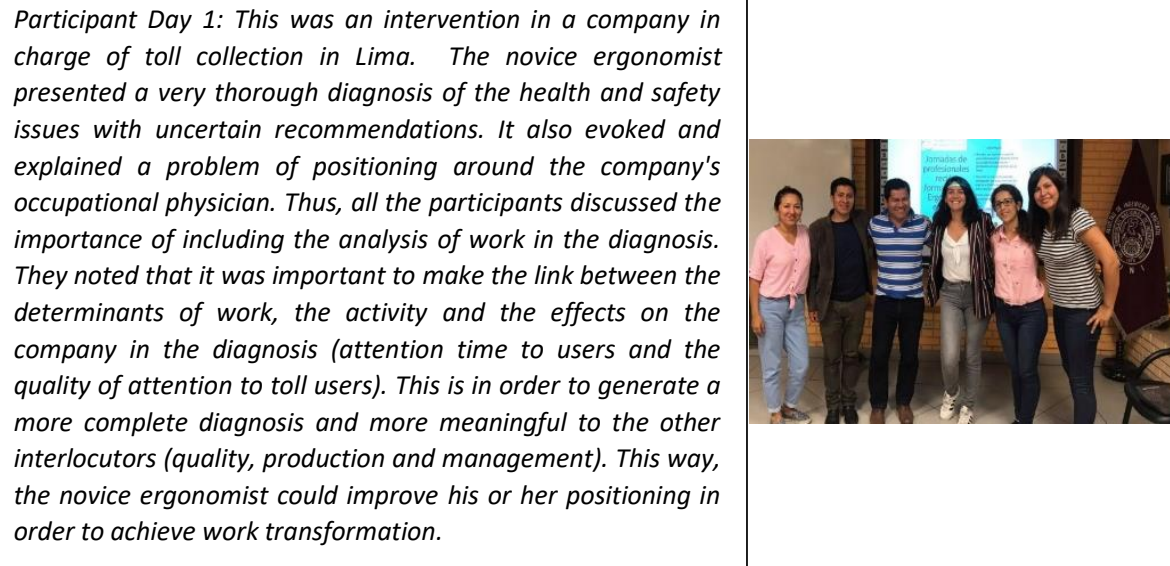

Fig.2. Summary illustrating the topics covered and participants picture from Day 1, 2019. 
The second day took place on June 8, 2019 in Arequipa from 14:00 to 18:00. The novice ergonomists presented their interventions and the topics discussed were varied. We show below a summary illustrating the topics discussed and the picture of the participants of the day.
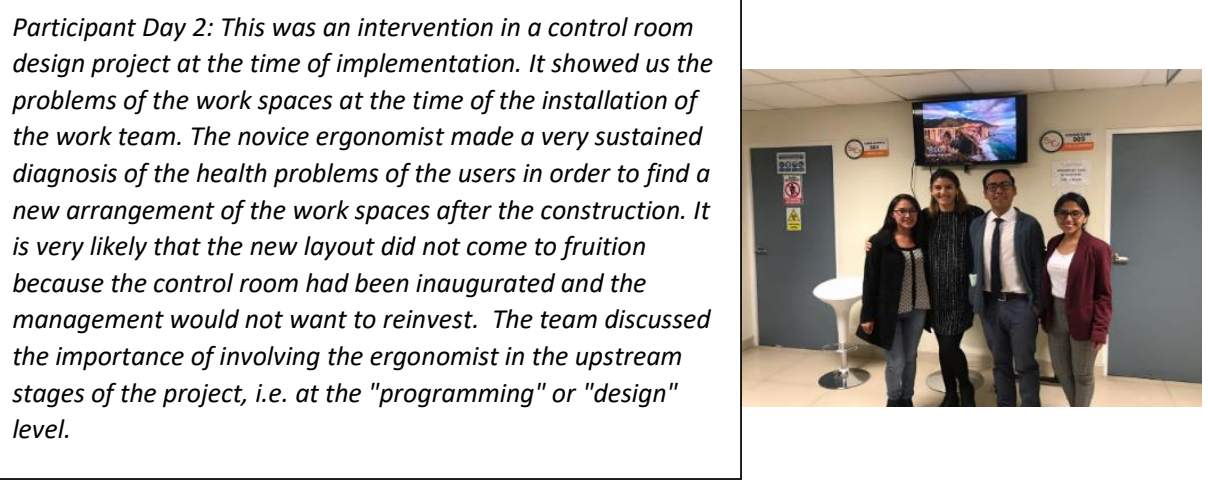

Fig.3. Summary illustrating the topics covered and participants picture from Day 2, 2019.

The after-Day : Just like in France, after the day we produce a report with the objectives of the day, the names of the participants, the topics discussed and a picture with all the participants that have authorized it. The idea is not to produce an analytical and exhaustive document, but to transcribe the issues raised, the brakes and levers identified, highlighting the links that could be made. This work allows us to reach a higher level of "sedimentation" of the exchanges (Cromer \& Mestanza, 2019). Likewise, participants receive a certificate of participation that novice Peruvian ergonomists request much more often than in France.

\section{Results}

During the two days, the novice ergonomists were able to present their current interventions and the topics discussed were varied. From these days and the exchanges that took place, the following elements and observations emerged:

- The profession of ergonomist in Peru. The influence of the two currents of ergonomics: human factor and the ergonomics of the activity, implies a certain difficulty in the practice of the novice practitioners because the idea of the profession of ergonomist is not the same for the various professionals (applicants and responders). Sometimes the applicants have human factor training and their expectations are different from those of the ergonomists answering the requests.

- The positioning of the ergonomist is very weak around the company's occupational physician. The main applicants in Peru are occupational physicians and health and safety team. They are very open to the transformation of work, but they generally have little decision-making power in organizations. Some novice ergonomists do not have strategies to improve their positioning to reach decision-makers and transform work. 
- The difference between implementing health and safety improvements and transforming work through ergonomic intervention. The improvements implemented in Peruvian companies are generally centered on the control of professional risks. However, these proposals of improvements can be incoherent with the real work and the functioning of the man at work which is not taken into account.

- Diagnosis is very intensively focused on the health problems of uses and very little on performance or quality. The lack of analysis of work in the training of ergonomists means that diagnoses are very focused on occupational health, which may be lacking in the diagnoses, as this does not always speak to decision-makers and therefore does not al-low the transformation of work to be achieved.

- The importance of including ergonomics in the design of work-spaces at the "programming " or " design " level. The participation of ergonomists in the management of projects is little known in Peru and they are generally called upon at the handover stage of a project when there are problems between users and workspaces.

This set of themes developed during the days shows the need for novice ergonomists to have spaces conducive to exchanges in order to build new practices in the convergence of the two currents of ergonomics.

Following the days, the participants were able to give us their feedback and one of the returns illustrates all the opinions of the participants:

"The reason I participated in the JPR day is because I looked for real solutions that other participants have integrated into their projects. This day was different from others (conferences, congresses, etc.) because I had the opportunity to show my mistakes, successes, and the progress of my work. In addition, I benefited from the experience of the other participants. It remains in my mind the importance of the ergonomist's positioning to achieve the transformation of the work. Since that day, I approach problems in work with a systemic approach, I do not look for an immediate solution, and otherwise I take a step back to find the root cause of the problem. During the next sessions, l expect to find experiences in other sectors, in other forms, to solve problems and in this way open my mentality to new ideas". (Cromer \& Mestanza, 2019).

The JPR days are very innovative sessions that allow novice ergonomists to identify their blockage problem in their interventions and find possible solutions. The participants are looking forward to future days because they find their problems in other novice ergonomists and they participate in the construction of new practices. In the same way, the recognition of the practice, influenced by the two currents of ergonomics, allows them to find new intervention strategies, compare their analyses, see the advantages and disadvantages of each practice, and enrich their own. These days also allow participants to build their network with fellow ergonomists and other professionals. 


\section{Conclusion}

Thereafter it will be necessary to make the days evolve. First of all by increasing the number of participants by improving the communication of the days through audiovisual support, ergonomics training, networking, etc.

Also, it will be important to select specific themes to be developed for the next days. Indeed, the large number of topics covered in the time allotted does not allow for in-depth and reflective exchanges. The topics are certainly infinite, but it is important to prioritize them in relation to the expectations of the participants. Indeed, if a precise theme is not developed, then the subjects risk being overlooked and multiplied, especially since the participants' functions can be very heterogeneous (occupational physicians, health and safety engineers, ergonomists, etc.). From these two days we have learned that it is necessary to focus the participants on a particular subject in order to gain more height on it and to meet the main objectives of the Junior Practices in reflection Committee.

By comparing the topics discussed during the JPR days in France with those of the days held in Peru, we find common issues such as the positioning of the ergonomist, working with stakeholders, demand analysis, etc.. Thus, whether we are in Peru, France, Quebec or elsewhere, some of the concerns of novice ergonomics practitioners are similar and have no borders.

\section{$\underline{\text { References }}$}

1. Schön, D. A. (1983). The reflective practitioner: How professionals think in action. New York: Ashgate.

2. Van Belleghem L. (2008). "Diversité des domaines d'intervention, nouvelles pratiques de l'ergonomie : qu'avons-nous encore en commun ? Fil rouge " in Actes des Journées de Bordeaux pour la Pratique, Mars 2008, p. 109-125

3. Schön, D. (1983). The reflexive practitioner: how professionals think in action. USA: Basic Books.

4. Schön, D. (1987). Educating the Reflective Practitioner. San Francisco: Jossey-Bass.

5. Cromer, D., Mestanza, M. (2019) «Debate de la práctica, un instrumento para la cons-trucción de la carrera del ergónomo que traspasa las fronteras», Laboreal [En línea], Volume 15 №2 | 2019.

6. Cromer, D., Elwert, L., Hubert, K., Francou, F., Couillaud, S. (2016). La comission SELF Jeunes Pratiques en Réflexion: de l'échange sur la pratique a son enrichissement, Symposium. Actes du 51ème Congrès de la SELF, Marseille 